\title{
Data Centers in the Kingdom of Saudi Arabia and their Role in Big Data Processing for Decision Support
}

\author{
Abdullah H. Al-Nefaiee ${ }^{1}$ \\ Alia M. Alhaif ${ }^{2}$ \\ Najah Algoblan ${ }^{2}$ \\ 'Department of Quantitative Methods, \\ School of Business, King Faisal University, \\ Saudi Arabia \\ ${ }^{2}$ Department of Library and Information, \\ College of Arts, Princess Nourah bint \\ Abdulrahman University, \\ Saudi Arabia
}

DOI: https://doi.org/10.36941/jesr-2022-0048

\section{Abstract}

The present research paper aims to identify the role of data centers in big data processing for decision support, the sources of information in data centers in data processing, the competencies of data specialists for processing big data to promote decision support, as well as the difficulties encountered by data specialist in data centers during the processing of big data. The authors adopted the descriptive analytical approach by designing and applying a questionnaire to a sample of (313) employees in data, documentation, and decision support centers in the public and private sectors in Riyadh, Saudi Arabia. The results showed that data centers play a major role in big data processing. Most of the participants (62.1\%) reported that feasibility studies are the most important source of decision support at the center. Moreover, (51.1\%) of the participants received training courses in statistical processing. Some difficulties face data centers, including the lack of the quality, maturity, processing, and maintenance of data. The study recommends the need to securely and adequately update the management systems and programs of data centers and to provide specialized training courses for data center employees.

Keywords: Data centers, Big data, Decision support, Data specialist

\section{Introduction}

Due to the rapid growth of data movement and the attempt of decision-makers to be wise and creative in making evidence-based decisions, institutions should develop comprehensive specialized information systems by establishing or reviving the role of data centers. These centers endeavor to find an effective means of providing decision-makers with substantial and safe information services in all forms and types (research studies- statistical reports) promptly. Data centers are one of the systems that could collect, process, categorize, and save data and information required by decision- 
makers to fulfill various functions. However, they currently face many challenges, especially under the technological domination in the age of knowledge (Nagara, 2011).

With the emergence of big data as a basis for modern research, data centers should be developed by employing highly qualified staff. Moreover, data specialists should be aware of such development to adapt and handle efficiently in the age of data (Reinhalter, Wittmann, and Block, 2015). Big data are a set of massive and complicated data that are hard to process and manage using traditional methods and applications. After collection in databases, data are searched, shared, analyzed, compared, and stored, whatever trivial they are, and results are concluded (Bieraugel, 2016).

Big data provide decision-makers with creative tools to understand the circumstances and inputs well and take proper decisions to achieve the desired goals and develop knowledge. They significantly affect continuous economic and social development (Ebtesam, 2018). Because of the importance of big data, many studies addressed them, such as Abdallah and Alhanaey (2018), Ebtesam (2018), Qeraty (2017), Alaklaby (2017), Bieraugel (2016), Bohdan (2015), Poleto et al. (2015), Philip and Zhang (2014), and Whitworth (2013) that stressed the importance of big data, the need to handle them, and continuous readiness to address the increasing expansion. Data have become very big, taking different forms, which affect the efficiency of their use by decision-makers. Moreover, the data specialist links the user and data access (Chen et al., 2016).

The importance of data centers and big data in decision-making is highlighted. However, to the authors' knowledge, no study has addressed the role of data centers in making big data-based decisions. Therefore, the present study aims to identify this role by exploring the nature and role of data centers in analyzing big data and define the types and efficiency of data resources in decisionmaking and formulating big data at data centers. It also explores the cultural, professional, and academic competencies of data specialists, presents them to decision-makers, and identifies the difficulties facing data centers in the lack of quality and processing of data.

\section{Statement of the Problem}

Data centers provide data services that undergo much economical and mathematical processing inside and outside the institutions because offering inaccurate data affects results. Because the institutions are aware of the importance and precise role of data centers under the revolution of data, big data have emerged. Many institutions form their organizational structures without implementing them in reality, causing a real administrative gap between the general vision and role of the institution and the state, on the one hand, and the tasks and roles of data centers in decision-making, on the other. Therefore, the present study redefines the role of data centers. Moreover, the level of awareness of the concept, characteristics, relevant issues, and fields of big data among data specialists at data centers requires exploration because most of the Arabic literature on big data focuses on libraries, addresses the topic theoretically (Alshawabka, 2018; Eltayeb and Alrayaee, 2018), and does not explore big data centers and their role in analyzing big data for decision support. The problem of the present study has been defined in the obscure role of data centers in analyzing big data for decision support due to the continuous and fast development of information technology. Thus, this role should be explored because of its importance at the level of individuals, groups, and governmental institutions. The study seeks to answer the major question "what is the role of data centers in analyzing big data for decision support?", which is divided into the following minor questions

1. What is the role of data centers in analyzing big data for decision support?

2. What are the data sources of data centers in analyzing big data for decision support?

3. What are the competencies of data specialists for analyzing big data for decision support?

4. What are the difficulties facing data specialists for analyzing big data for decision support? 


\section{Significance}

The study is significant because it tackles two critical concepts, namely decision-making and big data that represent the present and future information industry systems. The analytical statistics of big and institutional data should be examined, the capabilities and competencies of data specialists should be defined, and the difficulties they face should be resolved to provide high-quality services that may help keep up with the modern developments and potential challenges, especially in the manner data centers interact at the age of knowledge. A few studies addressed the examined issue in the Arab World. Hence, the present study tries to bridge the gap in the literature. Scientifically, the study makes some recommendations and suggestions to help the officials of data centers pay attention to analyzing big data for decision support. Practically, the results can benefit the administrations of data centers because it is important to identify the awareness of staff about big data and their need for training and qualification. They can also help decision-makers make appropriate decisions based on the needs of the data centers' staff to identify the efficiency of data sources in decision-making and analyzing big data. The results may benefit the directors of data centers and decision-makers in identifying the roles of the data centers' staff to activate the analysis of big data for decision support.

\section{Limits}

Spatial and human limits: A group of employees in data, documentation, and decision support centers in the public and private sectors in Riyadh, Saudi Arabia

Temporal limits: The field study was carried out in 2019-2020.

Object limits: The role of data centers, data resources, as well as competencies and difficulties of data specialists in analyzing big data for decision support

\section{Definition of Terms}

\subsection{Data Center}

According to Rousa (2010), a data center is a physical facility that organizations use to store important applications and data. A data center's design relies on a network of computing and storage resources that allow the delivery of shared applications and data. Its major components include routers, switches, firewalls, storage systems, servers, and application-delivery controllers.

The authors procedurally define a data center as an organization for collecting, integrating, and publishing data and information for decision support. This organization contains computers and storage devices connected to a network and utilized by other companies and organizations to organize, process, store, publish, and retrieve big data to serve beneficiaries, making it a pivotal point of daily processes.

\subsection{Big Data}

According to Canopy (2015), big data refer to a set of big or highly complicated data that require quick processing- problems of size/ variety/ speed- and are hard to handle using conventional databases and analytical tools, but they require software that works parallel to tens, hundreds, or thousands of servers. Big data are procedurally defined as a massive variety of data of multiple forms (written, audio, visual, etc.) and produced by various resources. To be utilized, they should be processed via unconventional technological media. In short, the term refers to big data in terms of quantity, speed, and diversity of resources processed by the Data Center in Riyadh, Saudi Arabia, to be provided to beneficiaries and decision-makers. 


\section{$5 \cdot 3$ Decision Support}

It is one of the computer-based data systems that facilitate interaction between people and information technology in producing information, which fits users' needs in decision support (Rasmy, 2007). It is procedurally defined as a computer-based system of automatic information used when the problem is disorganized as it examines the problem and collects and analyzes relevant data and information.

\section{Theoretical Framework and Literature Review}

6.1 Big data

\subsubsection{Characteristics}

Almasarawey (2019), Albar (2017), Mishra (2015), and Russom (2011) argue that big data should have a set of characteristics to benefit users, including:

1. Velocity: The speed of producing and extracting data to meet the demand because it is critical for decision making from access to data.

2. Veracity: These data are truthful, accurate, and updated.

3. Variety: The data are obtained from different sources, which help users choose the appropriate data and take time and effort to prepare them in a suitable form for analysis.

4. Volume: These data are big.

5. Suitability: Data are suitable if they help reduce uncertainty. They should be delivered to the decision-maker in time.

6. Reliance: Big data are reliable if they are free of error and material misstatement.

7. Completeness: How comprehensive are the data?

8. Timeliness: Data should be delivered to the decision-maker on time.

9. Ascertainablity: If used by many persons, data lead to the same result.

10. Accessibility: Only authorized persons access data.

11. Variance: Data are sometimes inconsistent, hindering their analysis and management effectively.

12. Truthfulness: It relates to data quality, which requires accurate analysis in terms of benefit and verifying the accuracy of resources.

\subsubsection{Types and resources}

Meguenani and Mokadem (2019) categorize big data into three types:

- Structured data: They are organized in tables or databases to be processed.

- Unstructured data: They represent the largest amount of data generated daily by personal writings, photos, videos, messages, and clicks on websites.

- Semi-structured data: They are a form of structured data but are not designed in tables or databases.

These data results are produced by a governmental or non-governmental program. They may emerge from an internal source, such as the different departments and sections and the staff of the various activities, including bills, purchase orders, received or issued cheques, as well as sales figures in the form of reports, notes, or registered discussions. According to Ebtesam (2018), the resources of big data include

- Transactional data result from transactions between two entities, e.g., credit cards of online transactions via mobile devices.

- Sensor network devices, such as satellite imagery (geographic and spatial images, remote sensing, crop statistics methods, road sensors, climate, tourism and events statistics, 
transportation, and population)

- Mobile phones data tracking devices and GPS

- Behavioral data, such as the number of research and views of a webpage

- Opinion-related data, such as comments on social media, messages, webpages, indicators of consumer trust, indicators of public opinion, and common attitudes

\subsubsection{Big data system}

Albar (2017) argues that big data cannot be utilized but with the participation of three parties:

a. A big data provider who provides data from different sources to the service provider generates data, generates metadata, finds open access resources online, and provides a statement of usable data.

b. A big data service provider who analyzes big data and provides infrastructure searches in data sources and collects data via direct request by data provider or online search, stores data, merges data, provides data analysis tools, and supports data administration, including data privacy, security, and ownership.

c. A big data service client (end-user), either a person or an institution, requests big data from the service provider and uses the outcomes of big data service.

The authors argue that the big data system does not succeed unless the different parties cooperate. There is no use in maintaining any data without analysis, processing, or use.

\subsubsection{Tools and methods of big data analysis}

With technology evolvement and data flow inside and outside institutions, faster and more efficient methods of data analysis are required. Such methods should be new and specialized for big data analysis. Moreover, there should be architectural structures for data storage and management. Consequently, big data affect everything from data and collection to processing to final decisions. Elgendy (2013) suggests a framework of big data, analytics, and decisions (B-DAD) that integrates the tools and methods of big data analysis in decision-making. The framework highlights different tools of storage, human management, and processing of data, as well as analysis, imaging, and evaluation of decision-making. Elgendy (2013) continues that the changes related to the analysis of big data cover three main areas: Big data storage and engineering, processing and analytics, and applied big data for discovering knowledge and making informed decisions.

\subsubsection{The importance of using and analyzing big data}

According to Alyahyaia (2018), Ahmed (2017), Jean-Charles and Yves (2014), and Manceau and Fabbri (2014), and based on the features of big data, their points of strength are

- Volume: Big data work with a high analysis ability (from terabyte to exabyte), which allows understanding users, as well as internal and external structure.

- Velocity: Big data help make the appropriate decision in time using high speed and performance software.

- Variety: Big data support institutions in analyzing all types of data via high performance and analysis programming platforms to conclude value and deep vision from various data.

- Ability to change: Big data can manage changes in the sample of data and information and give important results.

- Value: Without transforming data into value (this happens in big data analysis), there is no point in collecting them.

- Vision: Big data analysis helps view data using smart shapes, i.e., shortened tables and figures.

- Dissemination: It measures the speed of disseminating and sharing big data. 
Big data analysis helps achieve a more comprehensive and detailed understanding of the features and needs of individuals and groups by involving various parts of data in the analysis. Consequently, efficient communication and interaction and higher satisfaction are achieved. Additionally, big data promote the efficiency and accuracy of predictions (Ministry of Information and Communication Technology, 2014).

Because of the importance and analysis of big data, they were tackled by many studies. For instance, Alnaqera (2019) reviewed the perceptions of (483) information technology staff and higher management members on the impact of big data analysis on strategic flexibility domains. The results showed the participants' different levels of perception and the statistically significant relationship between the determinants of big data analysis and strategic flexibility domains. Almozayen (2019) explored the concept, types, resources, requirements, fields, and challenges of big data. The author also investigated the concept, forms, approaches, and advantages of knowledge integration in the Kuwait National Library. The findings illustrated that big data improve service performance and supports decision-making. There is a lack of staff specialized in big data management and training programs.

Bentayeb and Alriyaee (2018) explored the nature of big data, especially in libraries and information, and examined the tools, techniques, and new job titles in the field. They analyzed three applied big data projects using the exploratory and documentary approaches. They concluded that big data require developed technology in storing and processing and help define the goals of development and priorities. Mersal (2018) identified the importance and challenges of big data in libraries and compared the management of databases and big data. The results illustrated that big data management helps increase profits and decrease costs, but there are no improvement attempts by librarians.

Harper and Oltmann (2017) identified the impact of big data on information and using big data analysis in predicting future needs and defining the advantages and disadvantages of big data, including privacy. The findings showed the need to seek new methods of data analysis to provide library users with purposeful results and recommendations. Ghasemaghaei and Hassanein (2015) reported a significant relationship between big data analysis and organizational performance by applying it to a sample of middle leadership managers in Canada. The results indicated the need to pay greater attention to big data analysis to enhance organizational performance rates in intricate environments.

Sumithra (2014) examined the concept, features, and management of big data using data analysis software. The results forecasted the evolvement of big data with the challenge of extracting useful information from them. Ammu and Irfanuddin (2013) studied the challenges, opportunities, and benefits of big data. The authors reported that big data are important because of the importance of nanotechnology and cloud computing. Mouthaan (2012) explored the roles and analytical methods of big data in adding active value and competitive advantage to organizations. The study highlighted the relation between using big data and adding value or competitive advantage in organizations.

\subsection{Big data and decision support}

From the decision maker's perspective, big data can provide valuable information and knowledge from various resources, including scanners, mobile phones, websites, and social media, for decision support. When analyzed appropriately, big data provide chances to decision-makers thanks to the revolution of data obtained from supply chains, production operations, and customer behaviors (Cebr, 2012). Currently, institutions analyze internal data, e.g., sales, shipments, and inventory. However, there is a need for external data, including customer markets and supply chains. Big data can provide accumulated value and knowledge. With the evolution of big data, including structured ones, more informed decisions should be taken based on extracting meaningful data (Economist Intelligence Unit, 2012).

Elgendy (2013) developed the B-DAD framework that highlighted the tools and techniques of 
big data in decision-making. The first stage of decision-making is the intelligence phase, in which data are collected to determine problems and opportunities from internal and external resources. After collecting big data from defined sources, they are processed, stored, and migrated to the enduser. Preparing and processing data requires a high-speed network using ETL/ELT or big data analysis tools. The second stage is designed to develop and analyze potential work paths via a representational model of the problem. The framework includes three steps in this stage: Planning, data analysis, and analysis. The third stage is choice that includes evaluating the impacts of suggested solutions or work paths. The final stage is the implementation of the recommended solution.

With the growing amount of big data, institutions pay greater attention to data analysis and management and get as better benefits and vision as possible. Thus, they adopt big data analysis to maximize the economic value, make better and faster decisions, and reveal new patterns, emotions, and intelligence of customers. According to Manyika et al. (2011), big data enables companies to create new products and services, promote current products and services, and innovate business models. Therefore, business data analysis can be applied in different fields, e.g., customer intelligence, supply chain, performance, quality, risk management, and fraud detection. Manyika et al. (2011) also highlight the main industries that can benefit from big data analysis, including manufacturing, retail, central government, healthcare, telecommunications, and banking.

Because of their importance in decision support, big data were addressed by many studies. For instance, Maqnany and Sheblia (2019) identified the use, areas, and role of big data in sustainable development in decision-making. They explored their added value in changing society to achieve sustainable development goals and functioning to monitor progress and advance development. They suggested interest in using big data by decision-makers to achieve sustainable development goals. Alaklaby (2018) highlighted the importance of big data in decision support and evaluated the ITQAN system using the user interface and the manual of the system to develop the system to analyze big data efficiently that support decision-maker at the university. The study introduced a set of predictive models. It recommended developing more predictive models to develop the ITQAN system to manage big data that support the decision at the university.

Yadegaridehkordi et al. (2018) identified and categorized the factors of adopting big data and predicting their impact on the performance of manufacturing companies using the Decision Making Trial and Evaluation Laboratory (DEMATEL) method and Adaptive Neuro-fuzzy Inference Systems (ANFIS). The study identified these factors by reviewing literature and categorized them into technological, organizational, and environmental. Data were collected from (234) industrial managers involved in decision-making for IT procurement in Malaysian manufacturing companies. The results showed that technological factors (perceived benefits, complexity, technology resources, big data quality, and integration) were ranked first regarding big data adoption and company performance.

Adrian et al. (2018) introduced the results of expert opinion in verifying the factors influencing the implementation of big data analytics (BDA) to develop a BDA implementation evaluation model. The results reported the ten factors affecting big data, including the organizational domain (e.g., big data strategy, senior management support, commitment to resources, and organizational relationship), the people-related domain (e.g., analysis skills, management skills, and analysis culture), and the technology domain (including data infrastructure, information analysis, and quality). Al-Salmi and Araba (2018) aimed to overcome the challenge of the expansion and inflation of big data and the diversity of their resources in Oman. The results showed the important role of big data in institutional decision support.

Fattouh (2017) addressed big data and their role in decision support in libraries. The author reviewed the opinions of (178) Arab and foreign librarians regarding the possibility of big data in decision support. The results illustrated that using big data help libraries make decisions faster. AbdAal (2017) applied Data-driven Decision-Making (DdDM) as a new approach to hotel revenue management in Egypt and defined the different sources and types of data, as well as the methods of distributing data inputs used by revenue managers in hotels and their relationship to the efficiency of using the DdDM approach. The results highlighted the importance of using traditional and digital 
data to raise manager awareness. There was a positive relationship between data types and distribution sources and the efficiency of using DdDM.

Jassen et al. (2017) determined the factors that influence decision-making based on big data collected from different sources with diverse characteristics and processed by various entities to create a big data chain that requires accuracy, diversity, and speed amplified by the volume of big data, as well as relational and contractual management mechanisms to ensure the quality of big data and contextualize data. The results revealed that benefiting from big data is an evolutionary process where progressive understanding of the potential of big data and the routinization of processes play a crucial role. Brous et al. (2016) developed an approach to assess how data governance improves decision-making in asset management institutions. They defined data requirements to determine the conditions of current and future assets and recommended including data governance to enhance data quality for better decision-making in these institutions. Al-Eryani (2016) identified the opportunities and challenges in decision support on the web compared to traditional decision support systems, reviewed decision support techniques on the web, and compared them with traditional decision support systems. The findings reported that using web-based decision support allows great opportunities, but some challenges exist.

Based on the review of literature, the authors found out that the studies that addressed the relationship between big data and decision-making (e.g., Brous et al., 2016) are a conceptual approach to the academic, research, and technical importance of the topic and handled the applied technical part of the topic (e.g., Jassen, et al., 2017). These studies indicated the significance of free informational competition, which ultimately helps make informed decisions to benefit both institutions and people. Al-Salmi and Araba (2018) and Al-Eryani (2016) tackled the theoretical aspect, while Abd-Aal (2017) focused on the practical one of improving data-based decision-making, which agrees with the current study. The study agrees with the literature on several issues, including the importance of investing in big data after organizing and analyzing to support the decision-maker, which can be achieved when having qualified cadres and expert systems.

\subsection{Information and decision support centers}

Information is important for decision support, promoting the spirit of relations inside and outside the institution, and affording information in a framework of transparency and impartiality. The philosophy of the information center is based on the active integration between the departments of ministries and institutions by collecting, processing, analyzing, documenting, and publishing data internally and externally. This integration can be achieved by building partnerships between government agencies and the private sector, surveying public opinion towards issues and decisions before and after their issuance, creating communication channels with public opinion, cooperating with research centers, and establishing databases (Al-Shobaki, 2010).

Decision support is the way of quality-based decision-making. That is, decisions are made based on the quality and analysis of data to conclude appropriate solutions and strategies (Ibrahim, 2013). Soham (2013) argues that decision-making is a basic task in institutions, selecting accurately from alternatives. The decision is made based on the available information, previous decisions, and expectations.

According to Soham (2013), decision-making takes many stages, as follows:

a. Defining the problem: The management perceives a problem and deeply studies it to determine its source. A decision-maker should be aware of prioritizing the problems and define their types.

b. Identifying alternative: The available and possible alternatives are identified to handle the problem. Two alternatives should be available because having only one is not decisionmaking. Suggesting alternatives can be triggered by motivation.

c. Evaluation of alternatives: The decision-maker compares alternatives concerning merits, disadvantages, role in problem-solving, and appropriateness. 
d. Choosing the best alternative: It is the most important and accurate stage because the selected alternative should rely on the available circumstances and capabilities.

e. Decision-making: Implementing the chosen alternative by ensuring clear content and objectives of the decision, assigning roles clearly, having a good administrative structure that can fulfill responsibilities and have necessary supplies, making minor decisions, and providing human cadres.

f. Implementation and follow-up of the decision: An implementation plan is made by setting the time, stages, and roles of implementation. However, emerging problems should be considered and resolved.

6.4 Basic competencies and roles of data specialists for handling big data:

According to Shearer (2016), the data specialist should have a set of competencies, including:

a. Advanced programming skills

b. Ability to handle enormous amounts of data

c. Efficiency of providing access to data

d. Knowledge of data centers, repositories, groups, mechanisms of discovery, management, and analysis of techniques and tools

e. Awareness of data organization and coordination, intellectual property cases, data management plans, as well as the roles of data management, linking, and integration techniques.

Teague and Legeros (2014) and Xia and Wang (2014) argue that a data specialist should master these skills:

- Ability to collect and transform data into usable information and knowledge

- Mastery of information technology, computer-based technology, programming, and workrelated applications

- Collaboration, teamwork, as well as verbal, written, and virtual communication

- Work management in virtual environments

- Identifying the unique needs and desires of individual beneficiaries and institutions because standardized products no longer fit everyone's needs

- Continuous training and professional development

Teague and Legeros (2014) report that the most important roles of the data specialist concerning big data are

- Analyzing topics, issues, keywords, and resources to facilitate and guide borrowing styles in libraries and information institutions

- Defining frequent users of libraries and information institutions to raise awareness and provide better services

- Using web analytics programs to monitor website browsing and creating text and statistical reports

Persuad (2020) aimed to identify the precise competencies that employers are seeking for big data analytics professions. The results showed that employers look for staff with strong functional and cognitive competencies in data analytics, computing, and business, as well as social competencies and specific personality traits. The set of competencies varies according to job and task. Moreover, higher education institutions can design programs to meet market demand. There should be cooperation between public institutions, educational institutions, industry, and community organizations to ensure that training programs evolve with the evolving need for skills driven by dynamic technological changes. Al-Salmi and Araba (2018) concluded that professional institutions need data professionals to handle big data, while educational institutions need to understand this discipline to prepare experts who can use big data in strategic planning and decision-making. 


\section{Methodology}

\subsection{Method}

The study adopted the descriptive analytical approach that describes the phenomenon, collects data, categorizes and analyzes these data, and provides information (Al-Assaf, 2003).

\subsection{Population and sampling}

The population covered all the employees in data, documentation, and decision support centers in the public and private sectors in Riyadh, Saudi Arabia. The sample covered (313) participants to whom a questionnaire was applied for data collection in the following information centers:

1. Saudi Press Agency

2. Tourism Information Research Centre (MAS), the Saudi Commission for Tourism and National Heritage

3. Ministry of Justice

4. Business Intelligence and Decision Support Center, Transport Ministry

5. Saudi Food and Drug Authority

6. Communications and Information Technology Commission

7. Ministry of Human Resources and Social Development

8. General Authority for Statistics

9. Ministry of Housing

10. National Information Center

11. Ministry of Municipal and Rural Affairs

12. Information Center, Ministry of Foreign Affairs

Table (1) shows the description of the sample.

Table 1: Description of the sample according to variables

\begin{tabular}{|c|c|c|c|}
\hline Variable & Category & Frequency & $\%$ \\
\hline \multirow[t]{2}{*}{ Sex } & Male & 290 & 92.7 \\
\hline & Female & 23 & 7.3 \\
\hline \multirow[t]{4}{*}{ Age } & $20-35$ years & 95 & 30.4 \\
\hline & 36-5o years & 187 & $59 \cdot 7$ \\
\hline & 51-6o years & 26 & 8.3 \\
\hline & Above 60 years & 5 & 1.6 \\
\hline \multirow[t]{2}{*}{ Nationality } & Saudi & 301 & 96.2 \\
\hline & Non-Saudi & 12 & 3.8 \\
\hline \multirow[t]{9}{*}{ Current position } & Director of the information center & 15 & 4.8 \\
\hline & IT department employee & 15 & 4.8 \\
\hline & Statistics department employee & 92 & 29.4 \\
\hline & Publication department employee & 8 & 2.6 \\
\hline & Secretary and files & 9 & 2.9 \\
\hline & Support department employee & 9 & 2.9 \\
\hline & Data entry & 12 & 3.8 \\
\hline & Documentation department employee & 7 & 2.2 \\
\hline & Information management manager & 146 & 46.6 \\
\hline \multirow[t]{4}{*}{ Years of work experience } & Less than 5 years & 61 & $19 \cdot 5$ \\
\hline & 6-10 & 80 & 25.6 \\
\hline & $11-15$ & 63 & 20.1 \\
\hline & More than 16 years & 109 & 34.8 \\
\hline
\end{tabular}




\begin{tabular}{|l|l|r|r|}
\hline Variable & Category & Frequency & $\%$ \\
\hline \multirow{2}{*}{ Level of experience in handling big data } & Less than a year & 47 & 15.0 \\
\cline { 2 - 4 } & Two years & 51 & 16.3 \\
\cline { 2 - 4 } & More than three years & 188 & 60.1 \\
\cline { 2 - 4 } & None & 27 & 8.6 \\
\hline Total & 313 & 100 \\
\hline
\end{tabular}

Table (1) shows differences between the participants in the different variables.

\subsection{Tool}

After reviewing the relevant literature, the authors developed the tool (questionnaire) to collect data from the participants to answer the questions and achieve the study objectives. The final form of the questionnaire comprised two parts: Part I covers the primary data of the participants, whereas Part II comprises (36) items distributed to (4) domains on a three-point scale, as follows:

- The first domain: (3) available, (2) to some extent, and (1) unavailable

- The second and third domains: (3) yes, (2) undecided, and (1) no

- The fourth domain: (3) agree, (2) undecided, and (1) disagree

The participation degree (direction) to each domain is defined as follows: (1-1.66) low, (1.67-2.33) average, and (2.34-3) high.

\subsection{Validity}

\subsubsection{Reviewer's validity}

After developing the questionnaire, the preliminary form was presented to a group of reviewers to verify the relevance of each item to the domain, clarity of items, sound wording, and appropriateness. The reviewers agreed on more than $(80 \%)$ of the items, but some items were reformulated or deleted based on the reviewers' suggestions. The final form comprised (36) items.

\subsubsection{Internal validity}

According to the responses of the pilot sample of (30) participants, the internal validity of the items was estimated by calculating the Pearson correlation coefficient between the score of each item and the total score of the questionnaire, as shown in table (2).

Table 2: Pearson correlation coefficient between the score of each item and the total score of the questionnaire

\begin{tabular}{|c|c|c|c|c|c|c|c|c|c|c|c|}
\hline \multicolumn{4}{|c|}{ The first domain } & \multicolumn{2}{c|}{ The second domain } & \multicolumn{2}{|c|}{ The third domain } & \multicolumn{4}{c|}{ The fourth domain } \\
\hline $\begin{array}{c}\text { Item } \\
\text { no. }\end{array}$ & $\begin{array}{c}\text { Pearson } \\
\text { correlation } \\
\text { coefficient }\end{array}$ & $\begin{array}{c}\text { Item } \\
\text { no. }\end{array}$ & $\begin{array}{c}\text { Pearson } \\
\text { correlation } \\
\text { coefficient }\end{array}$ & $\begin{array}{c}\text { Item } \\
\text { no. }\end{array}$ & $\begin{array}{c}\text { Pearson } \\
\text { correlation } \\
\text { coefficient }\end{array}$ & $\begin{array}{c}\text { Item } \\
\text { no. }\end{array}$ & $\begin{array}{c}\text { Pearson } \\
\text { correlation } \\
\text { coefficient }\end{array}$ & $\begin{array}{c}\text { Item } \\
\text { no. }\end{array}$ & $\begin{array}{c}\text { Pearson } \\
\text { correlation } \\
\text { coefficient }\end{array}$ & $\begin{array}{c}\text { Item } \\
\text { no. }\end{array}$ & $\begin{array}{c}\text { Pearson } \\
\text { correlation } \\
\text { coefficient }\end{array}$ \\
\hline 1 & $.856^{* *}$ & 8 & $.837^{* *}$ & 1 & $.904^{* *}$ & 1 & $.936^{* *}$ & 1 & $.851^{* *}$ & 8 & $.833^{* *}$ \\
\hline 2 & $.874^{* *}$ & 9 & $.925^{* *}$ & 2 & $.878^{* *}$ & 2 & $.941^{* *}$ & 2 & $.865^{* *}$ & 9 & $.925^{* *}$ \\
\hline 3 & $.925^{* *}$ & 10 & $.885^{* *}$ & 3 & $.913^{* *}$ & 3 & $.955^{* *}$ & 3 & $.925^{* *}$ & 10 & $.886^{* *}$ \\
\hline 4 & $.925^{* *}$ & 11 & $.920^{* *}$ & 4 & $.896^{* *}$ & 4 & $.940^{* *}$ & 4 & $.924^{* *}$ & & \\
\hline 5 & $.858^{* *}$ & 12 & $.901^{* *}$ & 5 & $.916^{* *}$ & 5 & $.972^{* *}$ & 5 & $.860^{* *}$ & & \\
\hline 6 & $.859^{* *}$ & 13 & $.923^{* *}$ & 6 & $.905^{* *}$ & & & 6 & $.863^{* *}$ & & \\
\hline 7 & $.913^{* *}$ & 14 & $.883^{* *}$ & 7 & $.859^{* *}$ & & & 7 & $.914^{* *}$ & & \\
\hline
\end{tabular}


Table (2) illustrates that the correlation coefficients between the items and the total score of the domain are statistically significant at the level of (o.o1). All the correlation coefficients' values are high, indicating the high internal validity of the items.

\subsubsection{Reliability}

To calculate the reliability of the questionnaire, Cronbach's alpha of the domains was estimated, as shown in table (3).

Table 3: Cronbach's alpha of the domains

\begin{tabular}{|l|c|c|}
\hline Domain & No. of items & Cronbach's alpha \\
\hline The first domain & 14 & .872 \\
\hline The second domain & 7 & .805 \\
\hline The third domain & 5 & .784 \\
\hline The fourth domain & 10 & .880 \\
\hline Total & 36 & .893 \\
\hline
\end{tabular}

Table (3) shows the high reliability coefficients of the domains. The total Cronbach's alpha coefficient of the questionnaire was high and scored (.893), indicating the applicability and reliability of the questionnaire.

\section{Results and Discussion}

To answer the first question, the authors calculated the arithmetic mean, standard deviation, and rank of each item, as shown in table (4).

Table 4: Responses of the participants to the role of data centers in analyzing big data for decision support

\begin{tabular}{|l|l|c|c|c|}
\hline No. & Item & $\begin{array}{c}\text { Arithmetic } \\
\text { mean }\end{array}$ & $\begin{array}{c}\text { Standard } \\
\text { deviation }\end{array}$ & Rank \\
\hline 1 & The vision and mission align with the parent institution. & 2.57 & .602 & 3 \\
\hline 2 & There is a clear job structure for all employees. & 2.51 & .656 & 5 \\
\hline 3 & The job title for the center staff is appropriate. & 2.46 & .645 & 10 \\
\hline 4 & The administrative structure fits the distribution of departments. & 2.41 & .673 & 12 \\
\hline 5 & $\begin{array}{l}\text { The goals of the center are clear and applicable, and there is a clear strategic } \\
\text { action plan in accordance with the Saudi Vision 2030. }\end{array}$ & 2.50 & .631 & 7 \\
\hline 6 & $\begin{array}{l}\text { The center has an executive action plan for the digital transformation of } \\
\text { information resources. }\end{array}$ & 2.56 & .608 & 4 \\
\hline 7 & $\begin{array}{l}\text { All the information needed in decision-making is available, which helps } \\
\text { provide information to decision-makers quickly. }\end{array}$ & 2.46 & .593 & 11 \\
\hline 8 & Information is recorded, documented, and checked to save time. & 2.50 & .646 & 8 \\
\hline 9 & It helps provide a coherent chain of decisions. & 2.51 & .600 & 6 \\
\hline 10 & Data analysis and processing software are available to promote decision support. & 2.49 & .641 & 9 \\
\hline 11 & The center provides statistical data and periodic reports. & 2.64 & .567 & 1 \\
\hline 12 & There is a schedule for completing and reviewing statistics. & 2.64 & .600 & 2 \\
\hline 13 & There is a standard review of work and reports, such as the SMART standard. & 2.33 & .705 & 13 \\
\hline 14 & There are other quality standards, such as Sigma 6 or ISO. & 2.21 & .690 & 14 \\
\hline Overall mean & 2.49 & 0.63 \\
\hline
\end{tabular}


Table (4) illustrates that the role of data centers in analyzing big data for decision support (the first domain) is high with an arithmetic mean of (2.49), a standard deviation of (o.63), and a high degree of agreement. The low standard deviation of all items suggests the coherent opinions of the participants. While the item (the center provides statistical data and periodic reports) was ranked first, the item (there is a schedule for completing and reviewing statistics) was ranked second, and the item (the vision and mission align with the parent institution) was ranked third. The authors argue that data centers play several important roles for decision-makers by analyzing big data. Therefore, they should be activated, developed, and supported. These results agree with Watson (2014) that the success of big data analysis requires a clear plan, care, alignment between business strategies and information technology, vision, appropriate tools, and skilled staff. They also match the findings of Manyika et al. (2011) that the statistical analysis of big data can help establish new products and services and create business models based on methods, including ISO and LSS Lean Six Sigma.

To answer the second question, the authors calculated the arithmetic mean, standard deviation, and rank of each item, as shown in table (5).

Table 5: Responses of the participants to the data sources of data centers in analyzing big data for decision support

\begin{tabular}{|c|l|c|c|c|}
\hline No. & Item & $\begin{array}{c}\text { Arithmetic } \\
\text { mean }\end{array}$ & $\begin{array}{c}\text { Standard } \\
\text { deviation }\end{array}$ & Rank \\
\hline 1 & The source of interacting with the public & 2.59 & .711 \\
\hline 2 & The source of installing daily transactions in the center & 2.46 & .771 \\
\hline 3 & The nature of the center's activity & 2.54 & .711 \\
\hline 4 & $\begin{array}{l}\text { Providing information on other sources and linking them with the } \\
\text { work of the center }\end{array}$ & 2.49 & .777 \\
\hline 5 & The nature of the center's work necessitates archiving statistical data & 2.63 & 4 \\
\hline 6 & $\begin{array}{l}\text { Publishing the center's information to other government centers and } \\
\text { using them later through the other centers }\end{array}$ & 2.47 & .719 \\
\hline 7 & $\begin{array}{l}\text { It is not possible to analyze the center's data through the center's } \\
\text { employees. }\end{array}$ & 2.11 & 5 \\
\hline Overall mean & 2.47 & .805 \\
\hline
\end{tabular}

Table (5) shows that the data sources of data centers in analyzing big data for decision support (the second domain) are high with an arithmetic mean of (2.47), a standard deviation of (0.77), and a high degree of agreement. The low standard deviation of all items suggests the coherent opinions of the participants. While the item (the source of interacting with the public) was ranked first, the item (it is not possible to analyze the center's data through the center's employees) was ranked last. The authors argue that data centers vary in terms of sources of big data analysis, e.g., achieving statistical data and interacting with the public. However, there is a lack of reliance on the center's employees in doing the analysis. Thus, their competencies should be developed to enhance big data analysis for decision support. These findings agree with Abd-Aal (2017) that stressed the importance of data in making sound decisions. They match the results of Persuad (2020) and Adrian et al. (2018) that highlighted the importance of qualifying data specialists in data centers to analyze data in the center.

To answer the third question, the authors calculated the arithmetic mean, standard deviation, and rank of each item, as shown in table (6). 
Table 6: Responses of the participants to the competencies of data specialists for analyzing big data for decision support

\begin{tabular}{|c|l|c|c|c|}
\hline No. & Item & $\begin{array}{c}\text { Arithmetic } \\
\text { mean }\end{array}$ & $\begin{array}{c}\text { Standard } \\
\text { deviation }\end{array}$ & Rank \\
\hline 1 & $\begin{array}{l}\text { The center's employees are experienced in statistical work and data } \\
\text { monitoring. }\end{array}$ & 2.41 & .828 & 4 \\
\hline 2 & $\begin{array}{l}\text { The center's cadres can monitor data and conclude decisions to be } \\
\text { reported to their departments. }\end{array}$ & 2.53 & .751 & 2 \\
\hline 3 & $\begin{array}{l}\text { The center's cadres help make decisions based on the statistical } \\
\text { analysis of data. }\end{array}$ & 2.54 & .746 & 1 \\
\hline 4 & $\begin{array}{l}\text { The top management of the center pays attention to the cadres in the } \\
\text { regular meetings to promote the quality of work. }\end{array}$ & 2.48 & .781 & 3 \\
\hline 5 & $\begin{array}{l}\text { The center is interested in training the employees in new systems and } \\
\text { courses to develop work. }\end{array}$ & 2.36 & .844 & 5 \\
\hline Overall mean & 2.46 & \multicolumn{2}{|c|}{0.79} \\
\hline
\end{tabular}

Table (6) illustrates that the qualification of data specialists for analyzing big data for decision support (the third domain) is high with an arithmetic mean of (2.46), a standard deviation of (o.79), and (agree) response. The low standard deviation of all items suggests the coherent opinions of the participants. While the item (the center's cadres help make decisions based on the statistical analysis of data), the item (the center's cadres can monitor data and conclude decisions to be reported to their departments) was ranked second, and the item (the center is interested in training the employees in new systems and courses to develop work) is ranked last. The authors argue that data specialists enjoy competencies and good traits important for big data analysis for decision support. These results agree with Adrian et al. (2018) and Teague and Legeros (2014) concerning the investigation of the new roles and competencies of data specialists in institutions based on having capable human cadres with good skills. The authors stress the need for training these cadres in the effective management of big data. Eltayeb and Alrayaee (2018) reported that the concept of big data among data specialists in the Arab information centers is not clear enough. Thus, data specialists should be aware of the competencies of big data management and confront intricate functional and professional challenges to keep up with the latest developments in the field. The results agree with Persuad (2020) that employers look for skilled staff with certain traits and competencies, but employees often lack the competencies and need training in the technical, analytical, commercial, and interpersonal aspects.

To answer the fourth question, the authors calculated the arithmetic mean, standard deviation, and rank of each item, as shown in table (7).

Table 7: Responses of the participants to the difficulties facing data specialists for analyzing big data for decision support

\begin{tabular}{|c|l|c|c|c|}
\hline No. & Item & $\begin{array}{c}\text { Arithmetic } \\
\text { mean }\end{array}$ & $\begin{array}{c}\text { Standard } \\
\text { deviation }\end{array}$ & Rank \\
\hline 1 & Lack of specialized human cadres & 2.05 & .743 & 5 \\
\hline 2 & Lack of specialized training courses & 2.26 & .708 & 3 \\
\hline 3 & Insufficient, unclear, and inaccurate information & 2.03 & .713 & 6 \\
\hline 4 & Failure to provide data and information to the parties & 1.93 & .759 & 9 \\
\hline 5 & Lack of communication channels between internal and external parties & 1.96 & .728 & 8 \\
\hline 6 & Failure to fulfill the center's requirements by computer systems & 1.86 & .765 & 10 \\
\hline
\end{tabular}




\begin{tabular}{|c|c|c|c|c|}
\hline No. & Item & $\begin{array}{c}\text { Arithmetic } \\
\text { mean }\end{array}$ & $\begin{array}{l}\text { Standard } \\
\text { deviation }\end{array}$ & Rank \\
\hline 7 & Problems of networking, speed, and performance of the program & 1.99 & .764 & 7 \\
\hline 8 & $\begin{array}{l}\text { Updating the system and programs of the center's management appropriately } \\
\text { and safely }\end{array}$ & 2.34 & .721 & 1 \\
\hline 9 & Backup data via cloud backup & 2.14 & .736 & 4 \\
\hline 10 & Backup the servers' data regularly & 2.29 & .732 & 2 \\
\hline \multicolumn{2}{|c|}{ Overall mean } & 2.09 & \multicolumn{2}{|l|}{0.74} \\
\hline
\end{tabular}

Table (6) illustrates that the difficulties facing data specialists for analyzing big data for decision support (the fourth domain) are high with an arithmetic mean of (2.09), a standard deviation of (o.74), and moderate agreement. The low standard deviation of all items suggests the coherent opinions of the participants. While the item (updating the system and programs of the center's management appropriately and safely) was ranked first, the item (backup the servers' data regularly) was ranked second, and (failure to fulfill the center's requirements by computer systems) was ranked last. The authors argue that research in big data is modern and faces many obstacles. Receiving a moderate agreement suggests that a model should be developed to activate the role of data centers in Saudi Arabia concerning big data analysis for decision support. These results agree with Whitworth (2013) that big data analysis is a problem for many organizations because the adopted systems and tools should be developed to provide better results. They disagree with Alqarny (2016) that reported that the lack of suitable technical facilities, specialists, and financial resources are the most significant challenges to big data in Saudi Arabia. On the contrary, the results match the findings of Chaudhuri et al. (2011) that recommended using cloud computing to overcome updating the systems and programs of data management, meeting the infrastructure requirements, increasing flexibility, and decreasing cost. Chen and Zhang (2014) reported that big data draws the attention of authors and decision-makers and that cloud computing is the best method of big data analysis.

\section{Recommendations}

The study recommends updating the systems and programs of managing the center safely and appropriately for decision support. Specialized training should be provided, and data centers in Saudi Arabia should be restructured. Thus, the data quality monitors can become official employees in authority in a department concerned with data quality. Adequate and strong communication channels should be established. Moreover, government records should be employed for collecting statistical data. Laws and regulations should be enacted to maintain data privacy and security. Additionally, specialized teams of big data management should be established to benefit from their experience to achieve sustainability. The projects that serve digital transformation and achieving the Saudi Vision 2030 based on international trends should be increased. Institutions' exploitation of big data should be maximized to develop technical projects in various sectors to promote work effectively and have a clear impact on achieving work and its mechanisms, such as using cloud computing.

\section{Conclusion}

Decision support centers encounter challenges because of the rapid increase of big data and the need for accurate analysis to make appropriate and accurate decisions. Therefore, their data sources should be analyzed. The analysis methods help employ these data using new methods and tools across the different sectors of the government. After applying the questionnaire, the study concluded results that agree with the literature concerning the development of data centers and specialists and using developed statistical methods to obtain the most accurate results for decision support. 


\section{References}

Abd-Aal, E. (2017). Integrating data-driven decision making in the Egyptian hotel industry: Revenue management perspectives. Arabic Universities Union for Tourism and Hospitality Journal. 14(2):123-132.

Abdallah, K., Alhanaey, A. (2018). Big data in the libraries of Sultan Qaboos University: The impact of the role of directors as a moderate variable to benefit from big data in improving services (in Arabic). Iraqi Journal of Information Technology. 9(1): 23-52.

Adrian, C., Abdullah, R., Atan, Y., Jusoh, Y. (2018). Expert review on big data analytics implementation model in data-driven decision-making. Paper presented to the Fourth International Conference on Information Retrieval and Knowledge Management, Kota Kinabalu. doi: 10.1109/INFRKM.2018.8464770.

Ahmed, A. (2017). Big data... Features, opportunities, and strengths. http://www.alfaisal-scientifi.com/?p=2093

Alaklaby, A. (2017). Transforming big data into added-value (in Arabic). King Fahd National Library Journal.23(2):1103.

Alaklaby, A. (2018). Big data and decision-making at King Saud University: An evaluative study of ITQAN system. Journal of Information Studies \& Technology. 2. https://doi.org/10.5339/jist.2018.15

Al-Assaf, S. (2003). Introduction to research in behavioral sciences (in Arabic). Riyadh: Obeikan Library.

Albar, A. (2017). Big data and applications (in Arabic). https://www.kau.edu.sa/GetFile.aspx?id=28526o\&fn=Article-ofthe-Week-Adnan-Albar-o1-November-2017.pdf.

Al-Eryani, A. (2016). Systems of decision-making on the web: Challenges and opportunities (in Arabic). Yemen: Saba University

Almozayen, A. (2019). Big data and knowledge integration in national libraries: Kuwait National Library as a model (in Arabic). Scientific Journal of Libraries and Information. 1(2): 247-366.

Almasarawey, H. (2019). The role of an external auditor at the time of big data (in Arabic). International Islamic Economy Journal. 79(1): 93-106.

Alnaqera, A. (2019). Determinants of big data analysis and its impact on strategic flexibility: An applied study on pharmaceutical companies operating in Egypt (in Arabic). Scientific Journal of Economy and Commerce. 49(2): 503-596.

Alqarny, A. (2016). Big data in Saudi Arabia: reality and challenges (in Arabic). A paper presented to the conference of Administrative Development under Economic Challenges, Institute of Public Administration, Riyadh.

Al-Salmi, J., Araba, S. (2018). Big data and their role in decision support and strategic planning (in Arabic). A paper presented to the $24^{\text {th }}$ Annual Conference of Special Libraries Association-Arabian Gulf, Sultan Qaboos University, Muscat.

Alshawabka, Y. (2018). Awareness of the concept of big data among the staff of the academic libraries: A case study of the Library of the University of Jordan (in Arabic). A paper presented to the $24^{\text {th }}$ Annual Conference of Special Libraries Association- Arabian Gulf, Sultan Qaboos University, Muscat.

Al-Shobaki, M. (2010). Relationship between decision support systems and reengineering in Palestinian universities in Gaza (in Arabic). Master's thesis, Al-Azhar University, Gaza.

Alyahyaia, K. (2018). Big data: Challenges (in Arabic). A paper presented to the $24^{\text {th }}$ Conference "Big Data and Investment: Towards Cognitive Integration", Special Libraries Association- Arabian Gulf, Muscat.

Ammu, N., Irfanuddin, M. (2013). Big data Challenges. International Journal of Advanced Trends in Computer Science and Engineering. 2(1): 613-615.

Bentayeb, Z., Alriyaee, S. (2018). New roles of information specialists to deal with big data. Journal of Information Studies and Technology. 2(16): 1-15. https://doi.org/10.5339/jist.2018.16.

Bieraugel, M. (2016). Keeping up with big data. Association of College $\mathcal{E}$ Research Libraries. http://www.ala.org/acrl/publications/keepin g_up_with/big_data.

Bohdan, W. (2015). How do organizations prepare and clean big data to achieve better data governance? A Delphi study. Master's Thesis, Capella University.

Brous, P., Janssen, M., Herder, P. (2016). Coordinating data-driven decision-making in public asset management organizations: A quasi-experiment for assessing the impact of data governance on asset management decision making. In: Y. Dwivedi et al. (eds), Social Media: The Good, the Bad, and the Ugly. I3E 2016. Lecture Notes in Computer Science. Germany: Springer, Cham. https://doi.org/10.1007/978-3-319-45234-o_51.

Canopy, (2015). Big data for marketing: When is big data the right choice?. http://www.slideshare.net/canopyfilewhitepaper_big-ata-for-marketing.pdf.

Cebr, (2012). Data equity: Unlocking the value of big data. London: Cebr.

Chaudhuri, S., Dayal, U., Narasayya, V. (2011) An overview of business intelligence technology. Communications of the ACM. 54(8): 88-98. 
Chen, C. , Zhang, C. (2014).Data-intensive applications, challenges, techniques and technologies: A survey on Big Data. Information Sciences. 275: 314-347. DOI: http://dx.doi.org/10.1016/j.ins.2014.01.015.

Chen, X., Sheng, J., Wang, X., Deng, J. (2016). Exploring determinants of attraction and helpfulness of online product review: A consumer behaviour perspective. Discrete Dynamics in Nature and Society. https://doi.org/10.1155/2016/9354519

Ebtesam, H. (2018). The reality and horizons of big data in the Arab World: A case study of Saudi Arabia (in Arabic). International Journal of Economic Studie. 3: 122-173.

Economist Intelligence Unit, (2012) Big data. https://eiuperspectives.economist.com/technology-innovation/bigdata-o.

Elgendy, N. (2013). Big data analytics in support of the decision-making process. Master's Thesis, German University in Cairo, Egypt.

Eltayeb, Z., Alrayaee, S. (2018). New roles for data specialists to handle big data (in Arabic). Qatar: Hamad Bin Khalifa University.

Fattouh, A. (2017). Big data analytics and their role in decision support in libraries: An exploratory study (in Arabic). Journal of Arab Libraries and Information. 37: 4-40.

Ghasemaghaei, M., Hassanein, K. (2015). Online information quality and consumer satisfaction: The moderating roles of contextual factors- A meta-analysis. Information E Management. 52(8): 965-981.

Harper, L., Oltmann, S. (2017). Big data's impact on privacy for librarians and information professionals. Bulletin of the Association for Information Science and Technology. 43(4): 19-23. https://onlinelibrary.wiley.com/doi /epdf/10.1002/bul2.2017.1720430406.

Ibrahim, A. (2013). Information and strategic decision support (in Arabic), $3^{\text {rd }}$ ed. Cairo: Arab Group for Training and Publishing.

Jassen, M., Voort, H., Wahyudi, A. (2017). Factors influencing big data decision-making quality. Journal of Business Research. 70: 338-45. DOI:10.1016/j.jbusres.2016.08.007.

Jean-Charles, C., Yves, M. (2014). La revolution: Big data. France: Dunod.

Meguenani, S., Mokadem, C. (2019). Role of big data in supporting sustainable development in Arab countries. Journal of Information Studies and Technology. 1(4):1-14. https://doi.org/10.5339/jist.2019.4.

Manceau, D., Fabbri, J. (2014). Faire entrer la France dans la troisième révolution industrielle: le pari de l'innovation, note thématique 1, le Big Data, Mai.

Manyika, J., Chui, M., Brown, B., Bughin, J., Dobbs, R., Roxburgh, C., Byers, A. (2011). Big data: The next frontier for innovation, competition, and productivity. USA: McKinsey.

Maqnany, S., Sheblia, M. (2019). The role of big data in supporting sustainable development in the Arab countries (in Arabic). Journal of Information Studies E Technology. 4: 1-14.

Mersal, M., (2018). The role and importance of university libraries in big data management: A case study of the central library of the University of Khartoum (in Arabic). A paper presented to the $24^{\text {th }}$ Conference "Big Data and Investment: Towards Cognitive Integration", Special Libraries Association- Arabian Gulf, Muscat.

Ministry of Information and Communication Technology, (2014) Big data: Advantage-risk balance. Qatar: Ministry of Information and Communication Technology

Mishra, A. (2015). Information professionals and big data. International Journal of Advanced Research in Computer Science and Software Engineering. 5(9): 123-129.

Mouthaan, N. (2012). Effects of big data analytics on organizations' value creation. Master's thesis, University of Amsterdam, Netherlands.

Nagara, J. (2011). Application of group technology for design data management. Computer and Industrial Engineering. 34(1):255- 235 .

Philip, C., Zhang, C. (2014). Data-intensive applications, challenges, techniques and technologies: A survey on big data. Information Sciences Journal. 275 314-347 319.

Poleto T., de Carvalho, V., Costa, A. (2015). The roles of big data in the decision-support process: An empirical investigation. In: B. Delibašić et al. (eds.) Decision support systems $V$-Big data analytics for decision making (pp.10-21). New York: Springer.

Qeraty, H. (2017). Utilization of big data in technology companies and user privacy: An analytical study of user agreements and privacy policies of Google and Facebook (in Arabic). Master's Thesis, University 8 May 1945, Algeria.

Persuad, A. (2020). Key competencies for big data analytics professions: a multimethod study. Information Technology \& People. 34(1): 178-203. DOI 10.1108/ITP-o6-2019-0290.

Rasmy, M. (2007). A conceptual framework of decision support: Basics, requirements, and warnings (in Arabic). Jordan: Center for Decision Support and Future Studies. 
Reinhalter, L., Wittmann, R., Block, R. (2015). The library: Big data's boomtown. The Serials Librarian. 67(4): 363372. DOI: 10.1080/0361526X.2014.915605.

Rousa, M. (2010). Data center. https://searchdatacenter.techtarget.com/definition/data-center

Russom, P. (2011). Big data analytics. TDWI best practices report. CA, USA: TWDI.

Shearer, B. (2016). Librarians' competencies profile for research data management. https://www.coarrepositories.org/files/Competencies-for-RDM_June-2016.pdf.

Soham, B. (2013). Strategic planning and decision-making in libraries and information centers (in Arabic). Jordanian Journal of Library and Information Science. 48(4):13-70.

Sumithra, J. (2014). Mining big data: Current status and forecast to the future. International Journal of Computer Science and Information Technology Research. 2(3): 39-45.

Teague, E., Legeros, J. (2014). Big data's role in Information-centric organization. Information Outlook. 18(3). https://www.sla.org/wp-content/uploads/2014/12/BigDataRole.pdf.

Watson, H. (2014). Tutorial big data analytics: Concepts, technologies, and applications. Communications of the Association for Information Systems. 34(65): 1247-1268.

Whitworth, J. (2013). Applying hybrid cloud systems to solve challenges posed by the big data problem. Master's Thesis, The University of North Carolina, Greensboro.

Xia, J. \& Wang, M. (2014). Competencies and responsibilities of social science data librarians: An analysis of job descriptions. Colledge and Research Libraries. 75(3): 362-388.

Yadegaridehkordi, E., Hourmand, M., Nilashi, M., Shuib, L., Ahani, A. (2018). Influence of big data adoption on manufacturing companies' performance: an integrated DEMATEL-ANFIS approach. Technological Forecasting and Social Change 137: 199-210. 10.1016/j.techfore.2018.07.043. 